\title{
Article
}

\section{So what do we do with the rest of the day? Going beyond the pre-shot routine in professional golf}

Davies, Thomas C a, Collins, D., and Cruickshank, A.

Available at http://clok.uclan.ac.uk/12236/

Davies, Thomas C a, Collins, D., ORCID: 0000-0002-7601-0454 and Cruickshank, A. ORCID: 0000-0002-8893-2341 (2014) So what do we do with the rest of the day? Going beyond the pre-shot routine in professional golf. International Journal of Golf Science, 3 (2). pp. 163-175. ISSN 2168-7595

It is advisable to refer to the publisher's version if you intend to cite from the work. http://dx.doi.org/10.1123/ijgs.2014-0008

For more information about UCLan's research in this area go to http://www.uclan.ac.uk/researchgroups/ and search for <name of research Group>.

For information about Research generally at UCLan please go to http://www.uclan.ac.uk/research/

All outputs in CLoK are protected by Intellectual Property Rights law, including Copyright law. Copyright, IPR and Moral Rights for the works on this site are retained by the individual authors and/or other copyright owners. Terms and conditions for use of this material are defined in the policies page.

\section{CLoK}

Central Lancashire online Knowledge www.clok.uclan.ac.uk

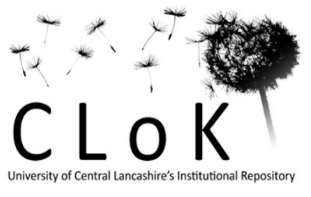


1 This is a pre-proof corrected manuscript, as accepted for publication, of an article published

2 by Human Kinetics in International Journal of Golf Science in December 2014, available

3 online: http://journals.humankinetics.com/ijgs-current-issue/ijgs-volume-3-issue-2-

4 december/so-what-do-we-do-with-the-rest-of-the-day-going-beyond-the-pre-shot-routine-in-

5 professional-golf

6

7 PLEASE REFER TO THE PUBLISHED VERSION FOR CITING PURPOSES

8

9

So What Do We Do With the Rest of the Day? Going Beyond the Pre-shot Routine in 


\section{Abstract}

Optimally focused attention has been shown to be a key psychological characteristic for peak performance in golf; a feature commonly achieved with a pre-shot routine. However, research to date has yet to address how a golfer's attention should best shift across the broader period of a whole game, or even including pre-event preparations, to support the preshot process and, ultimately, performance. Reflecting this knowledge gap, the present review aims to clarify current conceptual understanding and best practice against this wider perspective on attentional control, as well as highlight areas which must be considered for advances to be made. Specifically, research is required on the cognitive, behavioral, and temporal elements of routines used between shots and holes. Furthermore, to manage the attentional demands of the entire golf performance experience, such investigation also needs to explore the critical role of the support team and pre-tournament planning. 


\section{So What Do We Do With the Rest of the Day? Going Beyond the Pre-shot Routine in}

\section{Professional Golf Support}

The use of psychological skills has long been recognized as a significant differentiator between elite and non-elite sport performers (Durand-Bush, Salmela, \& Green-Demers, 2001; Salmon, Hall, \& Haslam, 1994; Stevenson, 1999; Weinberg, Burton, Yukelson, \& Weigand, 1993). In the case of golf, McCaffrey and Orlick (1989) outlined a number of mechanistic factors associated with performance excellence, including: commitment, quality practice, goal setting, imagery, practice planning, pre-tournament planning, tournament focus planning, distraction control, and tournament evaluation. More recently, a body of work has also investigated and supported the efficacy of pre-shot routines (for a comprehensive review see Cotterill, 2010). To date, however, little research has addressed the attributes required to successfully "fill the gap" between psychological skills applied in pre-tournament planning and those applied in shorter-term, pre-shot routines. In other words, there exists a significant knowledge gap on the optimal use of time between shots and holes which, chronometrically at least, represents the majority of "play" in any round. For the purposes of this paper, we focus on the professional game, where the significance of this omission is likely to be greater. Of course, given its essential role in performance, the focus and nature of performers' attention has a substantial history in sport literature (Garfield \& Bennett, 1984; Loehr, 1984; Privette, 1981, 1982; Ravizza, 1977). Defined as "engagement in the perceptual, cognitive, and motor activities associated with performing skills" (Magill, 2003, p.141), attention has, however, developed into a highly fragmented construct. Specifically, several categories are commonly applied in relation to attentional focus, including: internal and external (Nideffer \& Sagal, 1998; Wulf \& Prinz, 2001); broad and narrow (Nideffer \& Sagal, 1998); proximal and distal (Bell \& Hardy, 2009, McNevin, Shea, \& Wulf, 2003); associative and dissociative (Morgan \& Pollack, 1977; Schomer, 1986); endogenous (voluntary) and exogenous (non- 
voluntary) (Jonides, 1981; Posner, 1980); and content and characteristics (Bernier, Codron, Thienot, \& Fournier, 2011). Based on these studies, it can be inferred that high-level golfers should utilize information from visual, kinesthetic, and auditory sources to attend to different attentional foci depending on the situation they face.

Perhaps due to the predominant micro (i.e., pre-shot) focus of the literature, work to date has largely failed to address exactly what skilled golfers focus on before and after their swing, and during the considerable gap time which exists in between shots and holes. Moreover, by primarily considering performers' attention immediately preceding or during shot execution, this field of study has also overlooked how the intensity of a golfer's focus may change during an entire round (Hellstrom, 2009). Indeed, important tasks engaged beyond pre-shot and shot levels all require changes in the breadth and direction of attention. These include meso-level information processing before entering a pre-shot routine (e.g. course set-up, ball lie, pin position, wind speed/direction, technical changes made since last facing a similar shot or situation) and the return to meso-processing after shots (i.e., post-shot routine) (Hellstrom, 2009; Thomas, 2001). Taking this requirement against the lack of scholarly knowledge, work is needed which explores what attention should be focused on and how its intensity may change in the time preceding and proceeding shot execution.

Anecdotal evidence (cf. Carter, 2013; Scott, 2014; Townsend, 2014) suggests that there a number of potential distractions that professional golfers may face which will require effective meso-level attentional patterning. These distractions will vary in both number and scope, depending upon factors such as: tournament size and importance (e.g. Majors/the Ryder Cup versus a smaller tour event); standing within the tournament (e.g. holding the lead versus chasing the leader); and any tournament specific demands (e.g. the challenging rough at the US Open or the challenging greens at the Masters). The importance of effective attentional patterning at a meso-level was also demonstrated within research by Cohn (1991), 
who found that peak golf performance was associated with staying in the present, not focusing on past or future events (such as shots that have been hit or a potential score), and having a narrow focus of attention . Anecdotal evidence from players also suggests macroplanning can be used to cope with meso-level attentional demands such as moving on from dropped shots. For example Ogilvy (2012) discussed that part of his preparation for the US Open was using imagery to rehearse how he would react and cope with making more bogies versus a regular tournament.

Given that knowing what to focus on and how is essential for peak performance in elite golf (Hellstrom, 2009), especially given the number and scale of possible distractions, the purpose of this paper is threefold. First, we outline current understanding of macro-level (i.e., tournament preparation) and meso-level (i.e., shot preparation and response) planning in golf. Additionally, we also consider how both macro and meso processes may be enhanced via the golfer's work with their support team. Second, and based on existing literature, we discuss and outline current best practice for the patterning of golfers' focus in-between shots and holes. Finally, these preceding considerations are integrated to provide directions on how knowledge gaps in this area may be effectively filled.

\section{Macro- and Meso-Level Planning in Golf: Current Understanding}

\section{Macro (Pre-tournament) Planning}

Although McCaffrey and Orlick (1989) outlined the importance of a pre-tournament plan, this key performance feature has remained relatively under-researched in golf. Given that pre-tournament preparation includes a mental plan for course management and shot making strategies, as well as a logistical plan for the management of event requirements and responsibilities (McCaffrey \& Orlick, 1989), the comparative dearth of work on this topic is surprising, especially when heeding anecdotal evidence from players (Diaz, 2008; Ogilvy, 2012). Additionally, research in other sports has repeatedly highlighted the importance of a 
structured integration of mental skills and preparative behaviors before competitive performance (Beauchamp, Bray, \& Albinson, 2002; Judge, Bell, Bellar, \& Wanless, 2011; Malouff, McGee, Halford, \& Rooke, 2008.). We now consider some of the most important skills and behaviors which can (and should?) be applied in macro-level planning.

Pre-tournament imagery. Work from Paivio (1985) has shown that athletes can use imagery to rehearse skills (cognitive-specific imagery) as well as strategies of play and routines (cognitive-general imagery) prior to competition. Additionally, pre-tournament imagery can also serve a specific and general motivational function (Paivio, 1985) where athletes image the achievement of goals (motivational specific: Callow \& Hardy, 2001) and also physiological arousal and its effects (motivational general: Hall, Mack, Paivio, \& Hausenblas, 1998). Notably, general motivational imagery focused on performance arousal and mastery has been linked to a range of positive outcomes such as self-regulation and selfefficacy (Callow, Hardy, \& Hall, 2011; Feltz \& Riessinger, 1990; Hecker \& Kaczor, 1988; Vadocz, Hall, \& Moritz, 1997). Unfortunately, while cognitive and motivational imagery are valuable psychological pre-competition techniques, only Beauchamp, Bray, and Albinson, (2002) have integrated this perspective into golf. The consequent lack of understanding in this area is surprising given the clear anecdotal evidence from elite golfers which supports the use of pre-competition imagery (Ogilvy, 2012). Clearly, such "running through the possibilities" resonates with literature in other sports (cf. Hemery, 1986) and would seem to offer an important tool for pre-tournament preparation in golf.

Pre-tournament technical change/refinement. Evidence from coaches and players suggests that pre-tournament planning may also effectively include an element of technical change, or at least technical refinement. For instance, Diaz (2008) has previously described how David Leadbetter worked with Trevor Immelman prior to the 2008 Masters tournament to make specific technical changes which would permit better distance control on approach 
shots to greens; a specific challenge for that particular golf course. From this motoric perspective, sports psychology literature (e.g. Cumming \& Hall, 2002) suggests that the use of cognitive-specific imagery could help a player to implement a technical change prior to a tournament due to its functional equivalence with physical practice (Hall, 2001; Holmes \& Collins, 2001) and would therefore represent a core planning feature for particular events. Tactical planning. Facilitating golfers' pre-tournament imagery and technical change/refinement, as well as being a vital process in its own right, McCaffrey and Orlick (1989) have also earlier suggested that touring professionals hold mental plans for course management and shot-making strategies. As other work has identified that cognitive-general imagery may be used to image these plans and strategies (Paivio, 1985), the implication for golfers and their support teams is that mental models of an established tactical plan should be developed. However, to date, there has been no research addressing how such pretournament planning interacts with meso-level in-game thinking, the attentional demands of a round, and how any ad hoc changes in tactics may influence or be influenced by the player's attentional focus.

\section{The Meso Shot Cycle- Planning, Response and Clearing}

As it takes less than 5 seconds to address the ball and swing the golf club, and usually less than 45 seconds to plan and execute a shot, Bruce (1998) suggested that a golfer who shoots level par (usually 72 strokes) will be planning shots for $25 \%$ of their time and playing shots for $2 \%$ of their time on the course. This small percentage of time engaged in the planning and execution of shots clearly leaves large gaps of time in-between shots which golfers can fill with a number of potentially effective strategies. Grounding these strategies in established terminology, the most pertinent are pre-pre-shot preparation and a post-shot routine. 

the execution of motor skills (Hardy, Jones, \& Gould, 1996), there has been a surprising lack of literature on how golfers prepare prior to playing shots. In one of the few exceptions, Kirschenbaum, Owens, and O'Connor (1998) put forth their concept of Smart Golf which involves players' use of the acronym PAR: Plan, Apply and React. Similar to the broad external focus advocated by Nideffer and Sagal (2006), in which a golfer would assess the hole or shot they are about to play, Kirschenbaum et al.'s approach implies that golfers must plan certain elements of their shot prior to beginning their pre-shot routine. While the applicability of Smart Golf to elite players can be challenged over its simplicity, these authors' broader suggestion that players should engage in a certain amount of cognitive consists of and how it is best played out in professional golf performance. manner). Notably, this post-shot routine resonates with the model of attentional focus 
shot before rehearsing the correct movement (if required), and then shift back to a broad external focus ahead of the next shot. However, the idea of the 4-F model as an effective post-shot routine would only seem to be applicable when a player has hit a bad shot; suggestions of what elements should make up a post-shot routine after a good shot have not been forthcoming in the literature.

\section{Enhancing Macro and Meso Routines: Working with the Support Team}

Although it is the golfer who executes each shot, practice and evidence suggests that a golfer and their support team - which may include a coach, psychologist, conditioner but most notably the caddie - work together over macro- and meso- level planning processes (cf. Mackenzie, 1997; Reinman, 1999). Drawing on work on Shared Mental Models

(Mascarenhas \& Smith, 2011) (hereafter SMMs), the team decision making process will logically (or optimally) involve gathering, processing, integrating, and communicating information to arrive at task-relevant decisions. This does not necessarily require that a consensus be reached amongst team members, nor does it suggest that all team members are involved in all aspects of the decision (Mathieu, Goodwin, Heffner, Salas, \& CannonBowers, 2000). It does, however, require that each team member processes and filters raw data, applies expertise, communicates relevant information, and (appropriately) makes recommendations to others (Cannon-Bowers, Salas, \& Converse, 1993). As well as coordinating and synchronizing their actions with teammates, SMMs also help individuals to predict their colleagues' behavior and needs (Kraiger \& Wenzel, 1997; McIntyre \& Salas, 1995), Recognizing that differences in mental models will result in greater process losses (via the reduction in team coherence), the implication of these points is that members of the golf team (i.e., player and support staff) must hold common and/or overlapping representations of task requirements, procedures, and responsibilities (Mathieu et al., 2000). 
Of course, team members will not always agree on performance decisions. Indeed,

201

202

203

204

205

206

207

208

209

210

211

212

213

214

some disagreement would seem essential if decision making is to be optimized (Bowman, 1998). Accordingly, Cannon-Bowers et al. (1993) suggested that complex tasks dictate that multiple mental models are shared amongst team members. For elite golf, and to aid optimal decision making processes, the most relevant of these authors' frameworks would appear to be the task, team interaction, and team member models. Task models describe and organize knowledge about how the task is to be best accomplished (e.g., pre-tournament logistical procedures, course management strategies, predicted problems and contingencies). Team interaction models describe the roles and responsibilities of team members, interaction patterns, information flow, communication channels, role interdependencies, and information sources. Finally, team member models contain information which is specific to teammates, such as their knowledge, attitudes, preferences, strengths, weaknesses, and behavioral and emotional tendencies (Cannon-Bower et al., 1993; Mathieu et al., 2000). By addressing and optimizing each of these frameworks, it seems both logical and likely that the focus, functions, and interactions of the golfer and support team will therefore be enhanced. Indeed, and irrespective of the way which such SMMs are linked (e.g., communication processes, strategy, coordinated use of resources: Klimoski \& Mohammed, 1994), it is imperative that a golfer is supported by individuals who share his or her performance models and who are also willing to positively disagree at crucial but appropriate moments.

Professional tournament golf poses a number of challenges including large periods of time which need to be filled between shots and holes (Bruce, 1998; Lavallee, Bruce \& Gorley, 2004), distractions such as crowds and scoreboards, working with a support team before, during, and after performance (Lavallee et al., 2004), and controlling the breadth and direction of attentional focus over the whole performance (Hellstrom, 2009). To date, no studies have clearly addressed strategies used by players and their support team to deal with 
distractions and fill the gaps before and between shots and holes. Furthermore, while studies have considered the importance of a caddie in professional golf (Lavallee, 1998; Lavallee et al., 2004), no research has investigated how SMMs can effect team decision making and the attentional demands of their player. Finally, although research has shown that a narrow external focus of attention can be best for shot execution (Wulf \& Prinz, 2001), no studies have explored the pre-requisite shifts in attention at the pre-shot planning and post-shot analysis levels, and how support team members, their SMMs', and the information they supply (or indeed hold back) can influence these shifts.

Currently research from other sports and non-professional golf can partly fill gaps in knowledge around the attentional demands of the whole golf performance, effective mesolevel processes (pre and post shot), and the impact of team SMMs on performance. However, in order to fully fill these gaps and move the understanding of professional golf performance forward empirical research needs to be conducted in to these areas.

\section{A Current Best Practice Structure for Focus Patterning: What It Offers and What We}

\section{Need to Know}

With multiple factors and multiple agencies involved from pre-tournament to pre-shot levels (the latter being when total control is held by the player: Lavallee et al., 2004), planning in professional golf is clearly a complex process. To facilitate the development of knowledge and practice in this critical yet unexplored area, and based on the models of Nideffer and Sagal (2006) and Kirschenbaum et al. (1998), Figure 1 shows the current "best evidence" structure for the patterning of focus before and after a golf shot.

As conveyed, arrowed lines 1, 2, and 3 show the patterning of focus for playing a golf shot put forward by Nideffer and Sagal (2006), a conception which resonates with other work discussed earlier in our paper (e.g., Hellstrom, 2009; Kirschenbaum, 1997; Kirschenbaum et al., 1998, Thomas, 2001). However, this previous research does not answer a number of key 
questions relating to the patterning of focus during a full round of golf. For example, while Nideffer and Sagal (2006) propose that a player should start with a broad external focus for assessing the required shot (including wind strength and direction, distance to the flag, and the lie of the ball), what is not explained is when this information gathering begins, and where this information is gathered from. Notably, Lavallee et al. (2004) state that in some playercaddie relationships, the player merely asks the caddie for the distance to the flag whereas other caddies are far more involved in information gathering and decision making processes.

After assessing the shot, and as depicted in Figure 1, the golfer then moves to analyze the possibilities of how to play the shot. Nideffer and Sagal (2006) have stated that thoughts at this stage may include reflections on prior experiences in a similar situation against any changes in technique and equipment which the golfer has since made. Unfortunately, and once again, however, it is not clear where and indeed at what point the player shifts their attention during this process to gather relevant information. Following on from the analysis stage, the player's attention is then proposed to shift to a narrow and internal orientation which supports rehearsal of the technique required to execute the shot effectively (Nideffer $\&$ Sagal, 2006). At this stage, responsibility shifts to the player and the caddie can (or should?) no longer have any influence (Lavallee et al., 2004). Finally, and as attentional focus literature suggests (Wulf \& Prinz, 2001; Bernier et al., 2011), focus should then shift again to a narrow and external orientation to enable the most efficient execution of the skill (e.g. focus on a small, specific target).

Once a golfer has performed a shot, there appears to be a lack of consensus within the literature on exactly what they should then focus on and for how long. Interestingly, and suggesting that focusing for a whole round is not feasible given its lengthy duration, Tiger Woods (2001) has revealed that he allows himself 10 seconds to dwell on a previous poor shot (cf. the Fudge factor mentioned earlier) before focusing on the next shot. Indeed, 
Hellstrom (2009) has recently discussed the need for skilled golfers to plan and train for the ability to focus and refocus rather than engage a constantly "switched on" state. More realistic in this scenario therefore, and as suggested earlier in this paper, would be the golfer undergoing a post-shot routine (Finn, 2009) to "put away" a shot (be it good, bad, or indifferent), enter a period of relative relaxation, and then later switch back on for the next shot. As discussed previously, however, there has been no consensus within golf and sport psychology literature of what thoughts, behaviors, and timings should comprise an effective post-shot routine.

Indeed, consider again Kirschenbaum's (1998) 4-F model which suggests the player's first course of action after hitting a bad shot is to swear (Fudge) before progressing to Fix the swing. However, in order to effectively fix the swing, the golfer will need to perform some level of assessment on the shot, including where the ball started in relation to the target, where it finished, its trajectory, and the quality of the strike (Jacobs, 1993). Only then can the golfer work out if it was a swing fault that caused the poor shot or an error in decision making (e.g., choosing the wrong club). In an elite context, this is a process which could often involve the caddie, making yet more demands on the SMMs of the immediate support team. In this manner, a golfer's focus of attention should once again become broad-external to assess the reasons why they achieved (or suffered!) the given outcome (regardless of how good the shot was: Lyle, 2002) but then become narrow-internal to rehearse the correct action and "fix" the identified fault before assessing the next shot (Kirschenbaum, 1998).

\section{Directions for Future Research}

As identified throughout this paper, there are a number of gaps which need to be filled in order to refine and validate any model for the patterning of attentional focus during a round of golf. Most significantly, researchers need to develop knowledge of: (a) whether effective macro-planning can remove or reduce a need to attend to certain cues while playing (and thus 
decrease the attentional demands of a round); (b) the make-up of effective pre-pre and postshot routines and how these meso-level processes affect shot planning and responses; and (c) how SMMs between the player and support staff affect shot planning and responses.

Considering macro-planning first, although the research of McCaffrey and Orlick (1989) outlined the macro-planning processes which elite golfers engage prior to competition, research has not addressed how such preparation may (and should) affect in-game attentional focus and meso-planning. For example, is it possible to remove the need to attend to certain irrelevant and/or detrimental cues while playing with thorough macro-planning? Answering this question through long-term mixed methods tracking studies which collect and triangulate data on pre-tournament planning, in-competition perception, and performance data could positively assist golfers and their supporting practitioners in finding a way to focus on more important, task-relevant cues while playing. Secondly, while post-shot routines have been addressed in prior research (Finn, 2009; Kirschenbaum, 1997) no work has assessed their cognitive, temporal, and behavioral elements in professional golf. Accordingly, exploratory interviews which consider performers' perceptions on each of these factors, including their links with shot outcome and execution of a following pre-shot routine, would prove worthwhile. Additionally, it would also be useful to assess the potential variability in postshot routines as different shots afford a golfer more time to perform a post-shot routine than others. For example, a golfer who hits his/her tee-shot 250 yards into trees could have well over 5 minutes to reflect on his/her previous shot whereas a player on the putting green may only get 1 minute between his/her ball coming to rest and having to play again. Similar to the proposed merits of different pre-shot routines for different shots (cf. Cotterill et al., 2010), this should also lead researchers to tackle the important question of whether golfers should have different post-shot routines for different shots? For this purpose, action-research based inquiry which builds on the findings from explorative interviews would provide valuable 
insight into the optimal application of this skill in varying contexts. Furthermore, future research should also outline how systematic and well-practiced shifts in attentional focus within a post-shot routine can be used to aid planning for subsequent shots. To achieve this goal, "think aloud" protocols could be deployed which record and analyze thought processes as golfers move through their entire post-shot routine (Ericcson \& Simon, 1993).

Finally, we have also outlined the potential importance of SMMs in player-caddie relationships and how this element could impact on shifts in attentional focus with respect to meso-level information gathering. Notably, as previous investigation has tended to focus on the basic structure of caddying and ways to enhance its utility (Lavallee et al., 2004; Mackenzie, 1997), only an unpublished study by Lavallee (1998) has focused on the role that caddies play in maintaining players' attention and collecting/providing pertinent shot information.

While players' collection of information may simply be a matter of personal preference or experience, a survey of the comparative use of caddies and other strategies, as well as the consequent outcomes which they support, would seem desirable. Furthermore, consideration of which information gathering style to adopt should logically be based on more than personal preference alone. For example, assessing the use of "error taxonomies" to detect the circumstances in which things may work better or worse would also seem merited (e.g. Stanton \& Salmon, 2009). This gap needs closing and could be initially achieved though non-participant observation of players and caddies followed by interviews using stimulated recall (Patton, 2002; Lyle, 2003).

\section{Concluding Comments}

The ability to effectively regulate attention over the full preparation and execution phases of golfing performance is a critical yet unexplored area. Significantly, as both macroand meso-level planning processes shape and support in-game cognition, this broadened 

perspective on the allocation and patterning of attentional control carries significant promise

351 for advancing golf-specific theory and practice. Under this perspective, the investigation of

352 pre-event planning processes, the cognitive, behavioural, and temporal elements of routines

353 between shots and holes, and the interactions of a golfer's support team will provide a more

354 rounded and detailed picture of the demands and factors underpinning golfing success. Given

355 the impact which such work could deliver, we encourage researchers to carefully assess,

356 refine, and take up these recommendations as a matter of priority.

357

358

359

360

361 


\section{References}

Beacuchamp, M. R., Bray, S. R., \& Albinson, J. G. (2002). Pre-competition imagery, selfefficacy and performance in collegiate golfers. Journal of Sports Sciences, 20, 697705.

Bell, J. J., \& Hardy, J. (2009). Effects of attentional focus on skilled performance in golf. Journal of Applied Sport Psychology, 21, 163-177.

Bernier, M., Codron, R., Thienot, E., \& Fournier, J. F. (2011). The attentional focus of expert golfers in training and competition: a naturalistic investigation. Journal of Applied Sport Psychology, 23, 326-341.

Bowman, C. (1998). Strategy in practice. Harlow, Essex: Prentice Hall.

Bruce, D. (1998). Turn up, keep up, and shut up: The role of a caddie in male professional golf in Australia (Unpublished master's thesis). The University of Queensland, Brisbane, Australia.

Callow, N., \& Hardy, L. (2001). Types of imagery associated with sport confidence in netball players of varying skill levels. Journal of Applied Sport Psychology, 13, 1-17.

Callow, N., Hardy, L., \& Hall, C. (2001). The effects of a motivational general-mastery imagery intervention on the sport confidence of high-level badminton players. Research Quarterly for Exercise and Sport, 72, 389-400.

Cannon-Bowers, J. A., Salas, E., \& Converse, S. A. (1993). Shared mental models in expert team decision making. In N. J. Castellan, Jr. (Ed.), Current issues in individual and group decision making (pp. 221-246). Hillsdale, NJ: Erlbaum.

Carter, I. (2013). Justin Rose: US Open champion deserves more recognition. Retrieved from http://www.bbc.co.uk/sport/0/golf/25404887.

Cohn, P.J. (1991). An Exploratory Study on Peak Performance in Golf. The Sport Psychologist, 5, 1-14. 
Cotterill, S. (2010). Pre-performance routines in sport: Current understandings and future directions. International Review of Sport and Exercise Psychology, 3, 132-153.

Cumming, J., \& Hall, C. (2002). Deliberate imagery practice: the development of imagery skills in competitive athletes. Journal of Sports Sciences, 20, 137-145.

Diaz, J. (2008). Swing thoughts. Golf World, 61(34), 105.

Durand, M., Hall, C., \& Haslam, I. R. (1997). The effects of combining mental practice and physical practice on motor skills acquisition: A review of literature and come practical implications. Hong Kong Journal of Sports Medicine and Sports Science, 4, 36-41.

Durand-Bush, N., Salmela, J., \& Green-Demers, I. (2001). The Ottawa Mental Skills Assessment Tool (OMSAT-3*). The Sport Psychologist, 15, 1-19.

Ericsson, K. A., \& Simon, H. A. (1993). Protocol analysis: Verbal reports as data (Rev. ed.). Cambridge, MA: The MIT Press.

Feltz, D. L., \& Riessinger, C. A. (1990). Effects of in vivo imagery and performance feedback on self-efficacy and muscular endurance. Journal of Sport \& Exercise Psychology, 12, 132-143.

Fenker, R. M., \& Lambiotte, J. G. (1987). A performance enhancement intervention for a college football team: one incredible season. The Sport Psychologist, 1, 224-236.

Finn, J. (2009). Using mental skills to improve golfing performance: a theory-based case study for golf coaches. Annual Review of Golf Coaching, 4, 223-245.

Garfield, C.A., \& Bennett, H.Z. (1984). Peak Performance: Mental training techniques of the world's greatest athletes. Boston: J P Tarcher.

Hall, C. (2001). Imagery in sport and exercise. In R. N. Singer, H. A. Hausenblas, \& C. M. Janelle (Eds.), Handbook of Sport Psychology (pp. 529-549). New York: Wiley. 
Hall, C., Mack, D. E., Paivio, A., \& Hausenblas, H. (1998). Imagery use by athletes: development of the Sport Imagery Questionnaire. International Journal of Sport Psychology, 29, 73-89.

Hall, C. R., Schmidt, D., Durand, M.. \& Buckolz, E. (1994). Imagery and motor skills acquisition. In A. A. Shiekh, \& E. R. Korn (Eds.), Imagery in sports and physical performance. (pp. 529-549). New York: Wiley.

Hardy, L., Jones, G., \& Gould, D. (1996). Understanding psychological preparation in sport: theory and practice of elite performers. Chichester: Wiley.

Hecker, J. E., \& Kaczor, L. M. (1988). Application of imagery theory to sport psychology: Some preliminary findings. Journal of Sport \& Exercise Psychology, 10, 363-373.

Hellstrom, J. (2009). Psychological hallmarks of skilled golfers. Sports Medicine, 39, 845855.

Hemery, D. (1986). The Pursuit of Sporting Excellence. London: Collins.

Holmes, P. S., \& Collins, D. J. (2001). The PETTLEP approach to motor imagery: A functional equivalence model for sport psychologists. Journal of Applied Sport Psychology, 13, 60-83.

Jonides, J. (1981). Voluntary versus automatic control over the mind's eye's movement. In J. B. Long, \& A. D. Baddeley (Eds.), Attention and Performance IX (pp. 197-203). Hillsdale, NJ: Erlbaum.

Judge, L.W., Bell, R.J., Bellar, D. \& Wanless, E. (2011). Developing a Mental Game Plan: Mental Periodization for Achieving a 'Flow' State for the Track and Field Throws Athlete, The Sport Journal, 14, Retrieved from http://thesportjournal.org/article/developing-a-mental-game-plan-mentalperiodization-for-achieving-a-flow-state-for-the-track-and-field-throws-athlete/ 
Kirschenbaum, D. S. (1997). Mind matters: Seven steps to smarter sport performance. Carmel, IN: Cooper.

Kirschenbaum, D. S., Owens, D., \& O’Connor, E. A. (1998). Smart golf: Preliminary evaluation of a simple, yet comprehensive, approach to improving and scoring the mental game. The Sport Psychologist, 12, 271-282.

Klimoski, R., \& Mohammed, S. (1994). Team mental model: Construct or metaphor? Journal of Management, 20, 403-437.

Kraiger, K., \& Wenzel, L. H. (1997). A framework for understanding and measuring shared mental models of team performance and team effectiveness. In E. Salas, M. T. Brannick, \& C. Prince (Eds.), Team performance assessment and measurement: Theory, methods, and applications (pp. 63-84). Hillsdale, NJ: Erlbaum.

Lavallee, D. (1998). [The golfer-caddie partnership: Psychological skills and preferred attributes]. Unpublished raw data.

Lavallee, D., Bruce, D., \& Gorely, T. (2004). The golfer-caddie partnership: an exploratory investigation into the role of the caddie. Athletic Insight: The Online Journal of Sport Psychology, 6, Retrieved from http://www.athleticinsight.com/Vol6lss1/GolfCaddieRole.htm

Lee, C. (1990). Psyching up for a muscular endurance task: Effects of image content on performance and mood state. Journal of Sport \& Exercise Psychology, 12, 66-73.

Loehr, J. (1994). The new toughness training for sports. New York: Plume.

Lyle, J. (2002). Sports coaching concepts: A framework for coaches' behaviour. London: Routledge.

Lyle, J. (2003). Stimulated Recall: a report on its use in naturalistic research. British Educational Research Journal, 29, 861-878. 
MacIntyre, T., \& Moran, A. (1996). Imagery use among canoeists: A worldwide survey of novice, intermediate and elite slalomists. Journal of Applied Sport Psychology, 8, S132.

Mackenzie, R. (1997). A wee nip at the $19^{\text {th }}$ hole: A history of the St. Andrews caddie. Chelsea: Sleeping Bear Press.

Magill, R. A. (2003). Motor learning and control: Concepts and applications ( $7^{\text {th }}$ ed). New York: McGraw-Hill.

Malouff, J.M., McGee, J.A., Halford, H.T., \& Rooke, S.E. (2008). Effects of Pre-Competition Positive Imagery and Self-Instructions on Accuracy of Serving in Tennis. Journal of Sport Behavior, 3, 264-275.

Mascarenhas, D. R. D., \& Smith, N. C. (2011) Developing the performance brain: Decision making under pressure. In, Collins, D., Richards, H., and Button, A. (Eds.) Performance Psychology - Developing a Peak Performance Culture (pp. 245-267). London: Elsevier.

Mathieu, J. E., Goodwin, G. F., Heffner, T. S., Salas, E., \& Cannon-Bowers, J. A. (2000). The influence of shared mental models on team process and performance. Journal of Applied Psychology, 85, 273-283.

McCaffrey, N., \& Orlick, T. (1989). Mental factors related to excellence among top professional golfers. International Journal of Sport Psychology, 20, 256-278.

McIntyre, R. M., \& Salas, E. (1995). Measuring and managing for team performance: Emerging principles for complex environments. In R. Guzzo and E. Salas. (Eds.), Team effectiveness and decision making in organizations, (pp. 149-203). San Francisco: Jossey-Bass.

McNevin, N. H., Shea, C. H., \& Wulf, G. (2003). Increasing the distance of an external focus of attention enhances learning. Psychological Research, 67, 22-29. 
Morgan, W. P., \& Pollack, M. L. (1977). Psychological characterization of the elite distance runner. Annals of the New York Academy of Sciences, 44, 80-87.

Nideffer, R. M., \& Sagal, M. S. (1998). Concentration and attention control in training. In J. M. Williams (Ed.), Applied sport psychology: Personal growth to peak performance( pp. 296-315). Palo Alto, CA: Mayfield.

Nideffer, R. M., \& Sagal, M. S. (2006). Concentration and attention control training. In J. M. Williams (Ed.), Applied Sport Psychology: Personal Growth to Peak Performance (pp. 296-315). California: Mayfield.

Ogilvy, G. (2012). Open Success Often Hinges On The Ability To Handle Failure. Golf World, 65, 100.

Owens, D., \& Kirschenbaum, D. (1998). Smart golf: How to simplify and score your mental game. San Francisco: Josset-Bass.

Paivio, A. (1985). Cognitive and motivational functions of imagery in human performance. Canadian Journal of Applied Sport Sciences, 10, 22-28.

Patton, M.Q. (2002). Qualitative research \& evaluation methods, $3^{\text {rd }}$ ed. California: Sage.

Posner, M. I. (1980). Orienting of attention. Quarterly Journal of Experimental Psychology, $32,3-25$.

Reinmann, T. R. (1999). A caddie's life. The San Diego Union-Tribune, 1-4.

Salmon, J., Hall, C., \& Haslam, I. (1994). The use of imagery by soccer players. Journal of Applied Sport Psychology, 6, 116-133.

Schomer, H. H. (1986). Mental strategies and the perception of effort of marathon runners. International Journal of Sport Psychology, 17, 41-59.

Scott, S. (2014). Paul Lawrie backs friend to thrive under Ryder Cup pressure. Retrieved from http://www.thecourier.co.uk/sport/golf/paul-lawrie-backs-friend-to-thrive-underryder-cup-pressure-1.580174. 
508

509

510

511

512

513

514

515

516

517

518

519

520

521

522

523

524

525

526

527

528

529

530

531

532

Stanton, N.A., \& Salmon, P.M. (2009). Human error taxonomies applied to driving: a generic driver error taxonomy and its implications for intelligent transport systems. Safety Science, 47(2), 227-237.

Stevenson, M. (1999). The use of mental skills by male and female athletes (Unpublished master's thesis), University of Ottawa.Thomas, P. R. (2001). Cognitions, emotions and golf performance. In P. R. Thomas (Ed.), Optimising performance in golf (pp. 337-353). QLD: Australian Academic Press.

Thomas, P.R. (2001). Cognitions, emotions and golf performance. In P.R. Thomas (Ed.), Optimising performance in golf, (pp.337-53).Brisbane (QLD): Australian Academic Press.

Townsend, M. (2014, October). Mr Positive meets Mr Negative. National Club Golfer. 5456.

Vadocz, E., Hall, C., \& Moritz, S. (1997). The relationship between competitive anxiety and imagery use. Journal of Applied Sport Psychology, 9, 241-253.

Weinberg, R., Burton, D., Yukelson, D., \& Weigand, D. (1993). Goal setting in competitive sport: An exploratory investigation of practices of collegiate athletes. The Sport Psychologist, 7, 275-289.

White, A., \& Hardy, L. (1998). An in-depth analysis of the uses of imagery by high-level slalom canoeists and artistic gymnastics. The Sport Psychologist, 12, 387-403.

Woods, T. (2001). How I Play Golf. New York: Warner Books.

Wulf, G., \& Prinz, W. (2001). Directing attention to movement effects enhances learning: A review. Psychonomic Bulletin \& Review, 8, 648-660. 
533 Figure 1. A current best practice structure for focus patterning. Adapted from "Dimensions of

534 Attention”, by Nideffer \& Sagal 2006 in J. M. Williams (Ed.), Applied Sport Psychology:

535 Personal Growth to Peak Performance, p.384. Copyright 2006 by The McGraw-Hill

536 Companies, Inc.

537 And “Smart Golf” by Kirschenbaum, D.S., Owens, D. \& O'Connor, E.A, 1998, The Sport

538 Psychologist, 12, p.271-282. Copyright 1998 by Human Kinetics Publishers, Inc.

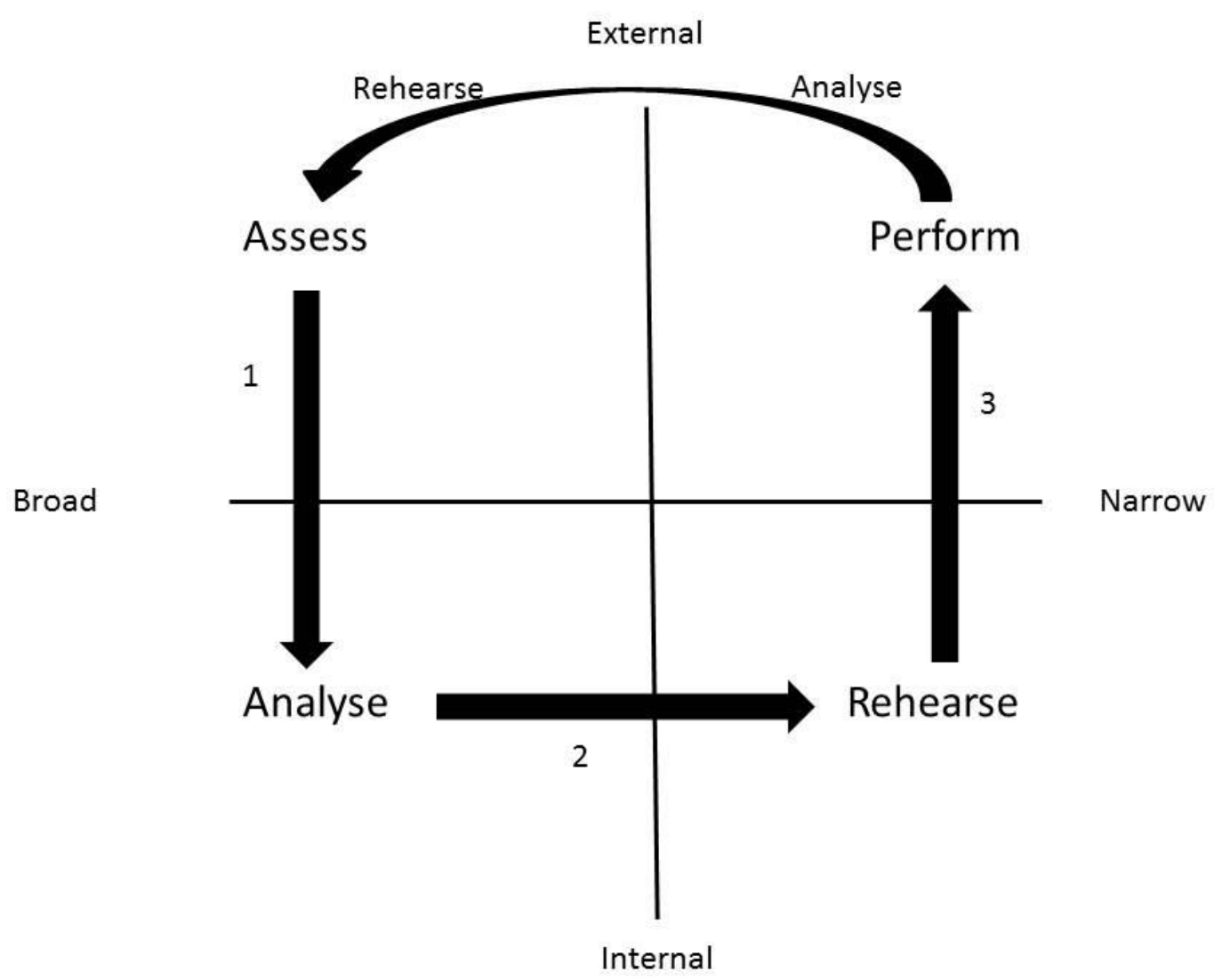

